\title{
Analisis Penyambungan Kabel Fiber Optik Akses dengan Kabel Fiber Optik Backbone pada Indosat Area Jabodetabek
}

\author{
Irfan Hanif, Defiana Arnaldy \\ Konsentrasi Teknik Ko mputer dan Jaringan \\ Teknik Informatika dan Ko mputer \\ Politeknik Negeri Jakarta \\ Depok, Indonesia \\ irfan.hanif.tik14@mhsw.pnj.ac.id,deffauth052016@gmail.com
}

Diterima: 13 Oktober 2017. Disetujui 15 Oktober 2017. Dipublikasikan November 2017

\begin{abstract}
Abstrak - Fiber optik (FO) adalah kabel berbahan serat optik yang menggunakan cahaya sebagai media transmisinya untuk mengirim data. FO terkenal akan kecepatannya dalam mentransmisikan data. Selain itu, FO memiliki bandwidth yang besar dan redaman yang kecil. Sehingga tidak heran jika FO sering menjadi unggulan oleh banyak provider, salah satunya Indosat. Dari semua kuntungan yang didapat dari FO terdapat beberapa kendala dan juga kekurangan dalam penggunaan FO. Salah satunya adalah kabel FO lebih rapuh dari jenis media transmisi yang lain, sehingga membuat redaman FO menjadi tinggi. Banyak faktor yang menyebabkan kabel FO memiliki redaman tinggi. Dan masalah yang sering ditemui diantaranya adalah kabel tertekuk (bending), disusul port dan konektor yang kurang bagus atau kotor, lalu sambungan FO yang kurang bagus. Untuk masalah sambungan yang kurang bagus, hal ini biasa terjadi pada proses pembuatan jalur baru atau penyambungan kabel FO backbone. Maka dari itu, untuk mencegah hal tersebut ada beberapa cara yang perlu dilakukan.
\end{abstract}

Kata Kunci: fiber optik, penyambungan fo backbone, pengukuran redaman kabel fo.

\section{PENDAHULUAN}

Perkembangan teknologi yang semakin pesat, dikuti pula dengan perkembangan telekomunikasi. Dua media jaringan telekomunikasi yang kita kenal saat ini yaitu kabel dan nirkabel, mempunyai keunggulan dan kelemahannya masing-masing, dan tergantung pada kondisi lapangan yang memungkinkan untuk mamakai salah satu dari media jaringan tersebut. Didaerah perkotaan besar seperti Jakarta, infrastruktur jaringan yang paling memungkinkan adalah menggunakan media kabel, salah satunya adalah kabel Fiber Optic atau biasa disingkat menjadi FO. Penggunaan FO lebih memungkinkan dikarenakan tata ruang Kota Jakarta dimana terdapat banyak gedung pencakar langit yang tingginya bervariasi. Alasan lainnya adalah, permintaan pelanggan akan konektivitas yang cepat dan handal. Kriteria in i adalah keunggulan kabel FO, dimana kabel FO adalah media yang menggunakan serat optik untuk mentransmisikan sinar atau cahaya dengan waktu yang cepat.

PT. Indosat yang berkantor pusat di Monas, telah mempunyai jaringan induk (Backbone) FO yang tersebar di daerah Jakarta dan sekitarnya. Selanjutnya disambungkan dengan kabel cabang (akses) FO untuk diteruskan ke pelanggan. Kegiatan penyambungan tersebut dinamakan branching. Saat ini belum semua gedung di Jakarta menggunakan media kabel FO dari Indosat. Dan seiring berjalannya waktu, datang pula pelanggan baru yang ingin menikmati layanan dari Indosat dengan media kabel FO. Sehingga kegiatan branching masih terus berlanjut.

\section{TINJAUAN PUSTAKA}

Perkembangan teknologi informasi dan komunikasi yang semakin cepat memerlukan media transmisi untuk mengimbangi perkembangan tersebut. Dengan menggunakan FO, optimalisasi jaringan menjadi lebih baik dikarenakan FO memiliki bandwidth yang besar serta minim redaman.

\section{A. Fiber optik (FO)}

1. Pengertian FO

FO adalah kabel berbahan serat optik yang menggunakan cahaya sebagai media transmisinya untuk mengirim data. FO terkenal dengan kecepatannya dalam mentransmisikan data. Untuk struktur kabel FO pada umu mnya terdiri dari bagian paling luar adalah jaket pelindung (coating), kelongsong (cladding/tube), dan inti (core) di bagian dalam[1]. 


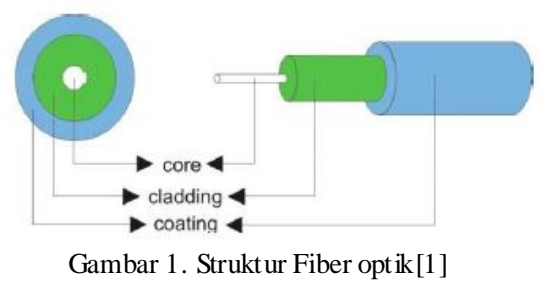

2. Jenis Kabel
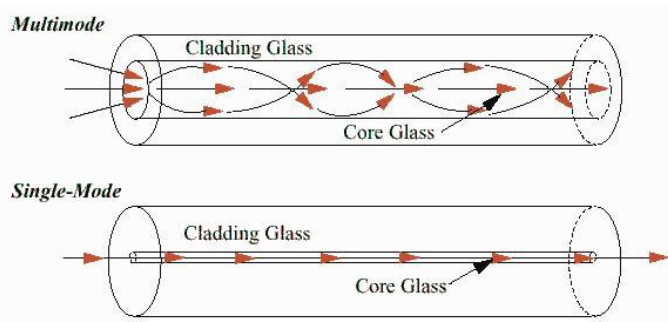

Gambar 2. Multi-mode (atas) Single-mode (bawah)

a. Single Mode

Kabel ini memiliki core yang lebih kecil dari multi mode sekitar 9 micron menggunakan wavelength 1300 atau $1550 \mathrm{~nm}$. Disebut single mode karena penggunaan kabel FO ini hanya memungkinkan terjadinya satu modus cahaya saja yang dapat tersebar melalui inti pada suatu waktu.

b. Multi Mode

Kabel ini memiliki core sekitar 50 sampai 100 micron, menggunakan wavelength 850 atau $1300 \mathrm{~nm}$. Disebut multi mode karena FO jenis ini memungkinkan ratusan modus cahaya tersebar me lalu i serat secara bersamaan

3. Model Kabel

a. Fiber optik Indoor

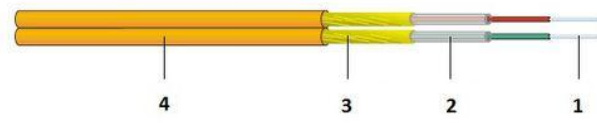

Gambar 3. Fiber optik Indoor

Kabel ini memiliki ciri-ciri menggunakan 2 core dan perbedaannya dengan kabel outdoor adalah kabel ini tidak memiliki tulang pelindung. Jadi lebih fleksibel dibandingkan dengan outdoor. Penempatannya biasa dilakukan di dalam ruangan[3].

b. Fiber optik Outdoor

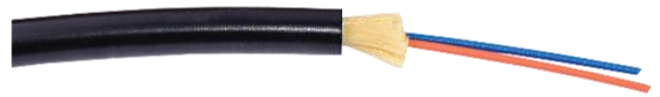

Gambar 4. Fiber optik Outdoor
Kabel ini memiliki ciri menggunakan 2 core serta mempunya tulang pelindung. Gunanya tulang pelindung adalah meminimalisir atau mencegah inti tidak terkena benturan ataupun tekukan yang berlebih. Penempatannya di dalam area gedung / ko mplek[2].

c. Fiber optik Backbone

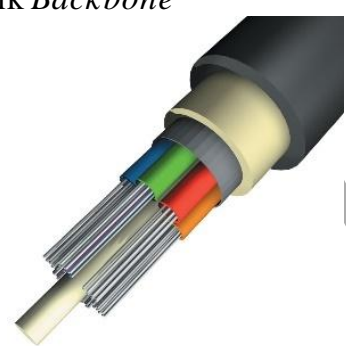

Gambar 5. Fiber optik Backbone

Kabel ini memiliki ciri menggunakan 24 sampai 144 core (standarnya). Dalam beberapa kasus, apabila kebutuhan lebih besar, maka core yang digunakan bisa mencapai 216 seperti yang digunakan. Dengan menggunakan kode warna optik "dalam dan luar". Penempatannya sendiri biasa melalui jalan-jalan protokol suatu wilayah. Untuk jumlah core 24 dan 48 biasa disebut kabel backbone untuk akses. Lalu untuk 96 hingga 216 disebut kabel backbone utama.

Kelebihan

a. Bandwidth lebar.

b. Tingkat keamanan yang lebih tinggi.

c. Tidak memakan banyak tempat (compact), dan ringan.

d. Tidak terganggu oleh elektromagnetik dan radio dikarenakan menggunakan media transmisi cahaya.

5. Kekurangan

a. Instalasi cukup sulit karena dibutuhkan ketelitian yang lebih.

b. Perawatan mahal dan sulit.

c. Paling tidak fleksibel diantara media transmisi kabel lainnya.

6. Kode Warna Fiber optik Backbone

TABEL 1. URUTAN WARNA KABEL FIBER OPTIK

\begin{tabular}{|c|c|c|c|}
\hline 1 & Biru & 7 & Merah \\
\hline 2 & Oren & 8 & Hitam \\
\hline 3 & Hijau & 9 & Kuning \\
\hline 4 & Coklat & 10 & Ungu \\
\hline 5 & Abu-abu & 11 & Pink \\
\hline 6 & Putih & 12 & Toska \\
\hline
\end{tabular}

Tabel 1 adalah standar pewarnaan pada Fiber optik 144 core kebawah. Untuk pewarnaan tube sama seperti core. Apabila lebih dari 144 core seperti yang digunakan Indosat yaitu 216 
core maka pewarnaan tube berubah (Tabel 2) namun core tetap sama seperti (Tabel 1).

TABEL 2. URUTAN W ARNA TUBE KABEL FIBER OPTIK 216 CORE INDOSAT

\begin{tabular}{|c|c|c|c|}
\hline 1 & Biru dalam & 10 & Coklat luar \\
\hline 2 & Oren dalam & 11 & Abu luar \\
\hline 3 & Hijau dalam & 12 & Putih \\
\hline 4 & Coklat dalam & 13 & Merah \\
\hline 5 & Abu dalam & 14 & Hitam \\
\hline 6 & Putih dalam & 15 & Kuning \\
\hline 7 & Biru luar & 16 & Ungu \\
\hline 8 & Oren luar & 17 & Pink \\
\hline 9 & Hijau luar & 18 & Toska \\
\hline
\end{tabular}

Contoh pembacaannya (kode 24/4T) adalah Tube 7 core 1 dan 2 artinya Tube merah core biru dan oren.

Contoh pembacaannya (kode 24/4T) adalah Tube 11 core 11 dan 12 artinya Tube abu luar core pink dan toska.

TABEL 3. KODE KABEL FIBER OPTIK BACKBONE

\begin{tabular}{|c|c|c|c|}
\hline Kode & Core & Tube & Core/Tube \\
\hline $24 / 4 \mathrm{~T}$ & 24 & 4 & 6 \\
\hline $36 / 6 \mathrm{~T}$ & 36 & 6 & 6 \\
\hline $36 / 3 \mathrm{~T}$ & 36 & 3 & 12 \\
\hline $48 / 8 \mathrm{~T}$ & 48 & 8 & 6 \\
\hline $48 / 4 \mathrm{~T}$ & 48 & 4 & 12 \\
\hline $72 / 6 \mathrm{~T}$ & 72 & 6 & 12 \\
\hline $96 / 8 \mathrm{~T}$ & 96 & 8 & 12 \\
\hline $216 / 18 \mathrm{~T}$ & 216 & 18 & 12 \\
\hline
\end{tabular}

Tabel 3 adalah tipe kode fiber optik yang digunakan oleh Indosat.

7. Peralatan Fiber optik

a. Alat ukur redaman optical

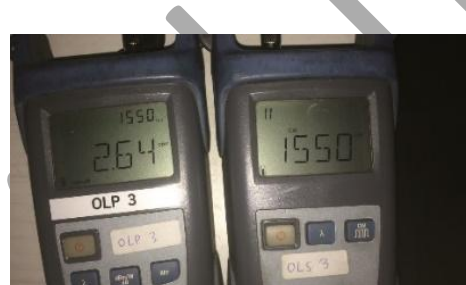

Gambar 6. Optical Power Meter (kiri) Optical Light Source (kanan)

Memiliki fungsi mengukur redaman pada jalur optik yang dilalui. Optical power meter berfungsi sebagai penerima sinyal dari sinyal yang dikirim oleh optical light source.

b. Optical Time Domain Reflector (OTDR)

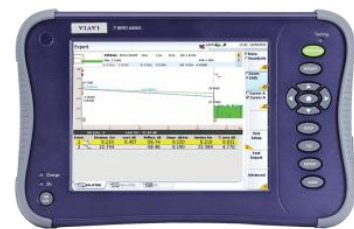

Gambar 7. Optical Time Domain Reflector

OTDR adalah Alat untuk mengukur jarak serta redaman pada jalur optik. Dalam beberapa merek fungsi OTDR juga dapat berfungsi sebagai Light Source (OLS) dan Power Meter (OPM).

c. Cleaver dan Striper
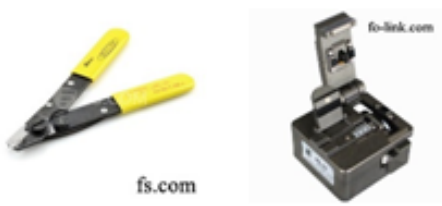

Gambar 8. Striper (kiri) dan Cleaver (kanan)

Striper berfungsi sebagai pengupas tube dari core dan membersihkan serbuk yang menempel pada core. Sedangkan cleaver berfungsi sebagai pemotong core dengan rapih.

Splicer

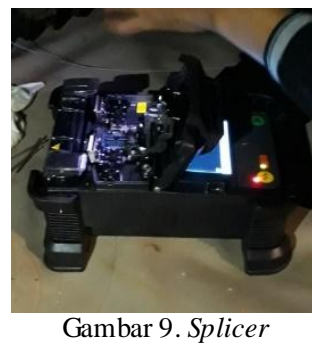

Berfungsi sebagai alat penyambung 2 core yang terpisah menjadi 1 dengan cara (fusion) yaitu teknik melebur.

\section{PEMBAHASAN}

A. Pembuatan Konfigurasi

Langkah pertama adalah pembuatan konfigurasi untuk pembuatan jalur baru. Berikut contoh konfigurasi.

Arti Konfigurasi (Gambar 10) adalah : Existing, yaitu : Konfigurasi yang sedang dipakai; Rearrangement : Pengaturan ulang (arah jalur);

Konfigurasi yang sedang digunakan (existing) adalah :

- Pada sisi ODF di Mitsun port yang digunakan ODF nomer 1 , baris 3 , kolom 8 , core 5 dan 6 (ODF1_3/8/5\&6) 
- Pada sisi HH kabel akses tube biru core $1 \& 2$ disambung kabel backbone hitam core $5 \& 6$

- Untuk konfigurasi selanjutnya cara bacanya sama.

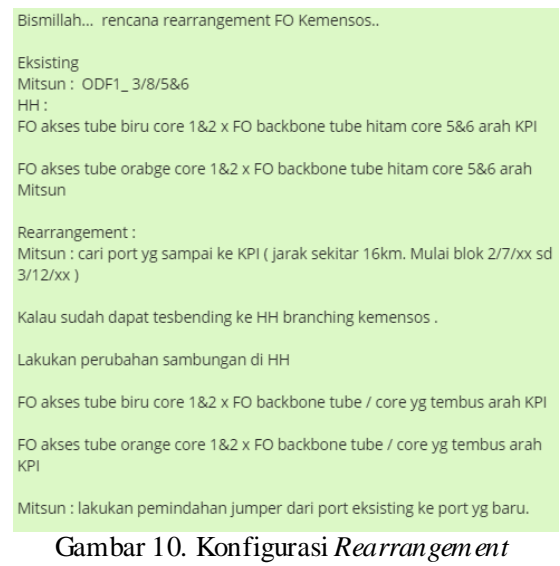

Konfigurasi baru versi (rearrangement) adalah :

- Mencari port baru di ODF arah KPI (jaraknya $16 \mathrm{~km}$ ) pada port $2 / 7 / \mathrm{xx}$ sampai $3 / 12 / \mathrm{xx}(\mathrm{xx}$ artinya 1-12).

- Untuk sisi HH, rencana barunya tube biru core $1 \& 2$ disambung kabel backbone, tube dan core disesuaikan dengan port pada ODF.

Selanjutnya adalah bagian eksekusi. Mulai dari pengetesan core, pengupasan, penyambungan serta perapihan dan dokumentasi.

\section{B. Mengecek Tube dan Core}

Cara mengecek tube dan core benar atau tidaknya bisa dilaku kan dengan melakukan beberapa tes berikut diantaranya :

1. Tes Laser Pointer

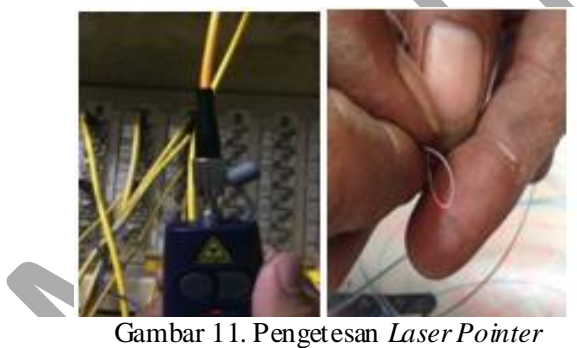

Cara ini cukup mudah karena dibandingkan dengan cara bending. Bila salah memperkirakan core. Kita dengan mudah menemukannya dengan cara me lihat core mana yang diterangi oleh laser.

\section{Bending Tes}

Bending sendiri memiliki arti tekuk. Artinya tes ini dilakukan dengan cara menekuk kabel FO tetapi tidak sampai tekuk sudut siku, karena akan patah tentunya. Penekukkan dilakukan dengan membuat pola lingkaran pada core terkait. Alat yang digunakan bisa OLS dan OPM atau OTDR. Berikut contoh menggunakan alat OTDR untuk menemukan core pada kabel backbone[2].

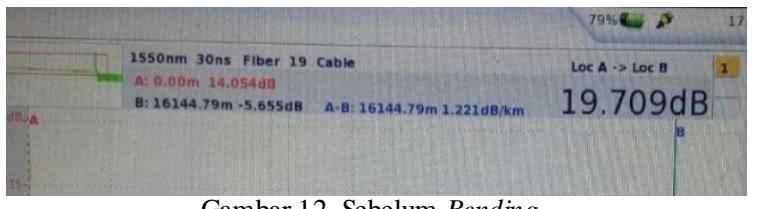

Gambar 12. Sebelum Bending

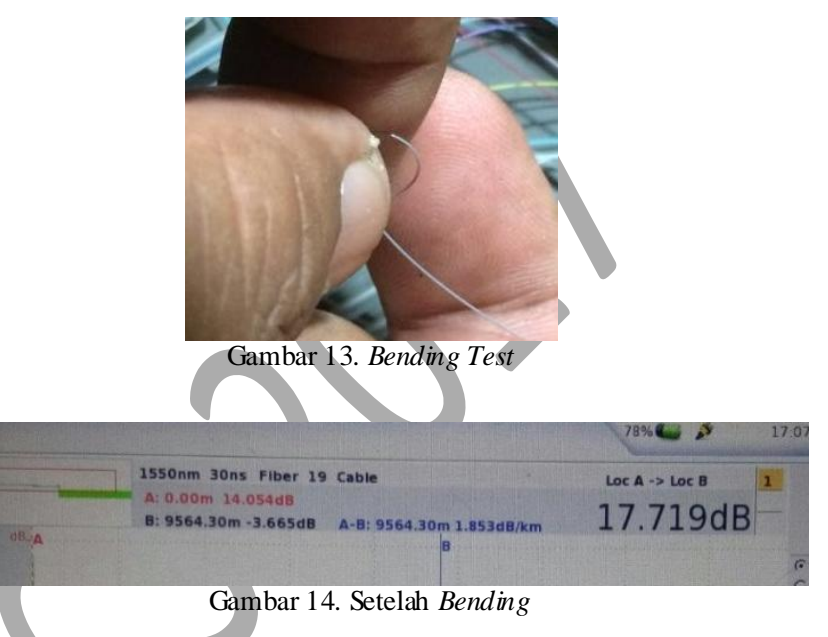

Perhitungannya seperti berikut :

Jarak total : $16.1 \mathrm{Km}$

Jarak server - $\mathrm{HH}: 9.5 \mathrm{Km}$

Jarak HH - Pelanggan :

Jarak total - jarak server ke $\mathrm{HH}$

$16.1 \mathrm{Km}-9.5 \mathrm{Km}: \underline{\mathbf{6 . 6} \mathrm{Km}}$

Hasil tersebut dicocokan dengan konfigurasi existing dan skema jalur. Bila cocok benar bahwa core tersebut merupakan jalur yang dimaksud.

\section{Proses Penyambungan}

Setelah core didapat. Tahap berikutnya adalah proses penyambungan (splicing). Pada proses ini core yang dipilih dibersihkan dengan alkohol kemudian dikupas dengan stipper dan dipotong dengan cleaver selanjutnya splicing core yang sudah dibentuk tadi dengan alat splicer[3].

Splicing yang digunakan adalah model splicing fusion (menggabungkan dengan cara meleburkan dua fiber menjadi satu). Dan batas toleransi redaman splicing maksimal sebesar 0.02 dB.

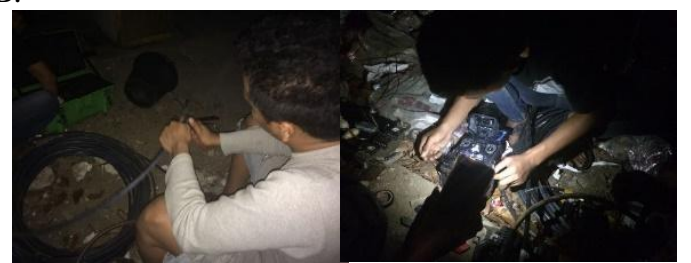

Gambar 15. Proses Pengupasan (kiri) dan Penyambungan T eknik Fusion (kanan) 
Core hasil splicing dibungkus dengan tube splice agar core terhindar kontak lansung dengan benda asing. Kemudian disusun dan disimpan dalam splice tray.

Dalam satu splice tray terdapat satu hingga dua tube. Tidak lebih namun boleh kurang. Lalu untuk sisa tube yang tidak digunakan (gantung) hanya dililitkan dalam closure bersamaan dengan splice tray seperti pada Gambar 16.

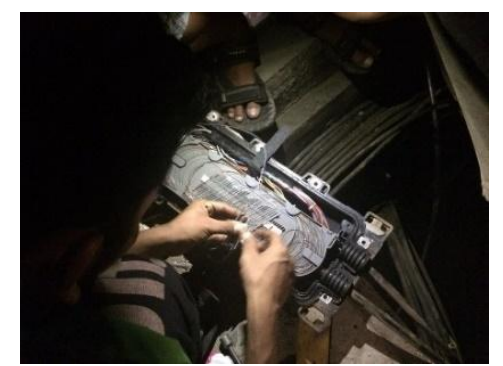

Gambar 16. Penyusunan Core Pada Splice Tray

Bila sudah rapih masukan closure ke dalam HH. Tutup kembali $\mathrm{HH}$ dan jangan lupa mengabadikan setiap kegiatan dalam bentuk foto untuk keperluan doku mentasi (Gambar 17).

\section{Pengetesan Redaman Jalur}

Pada waktu berikutnya setelah kegiatan branching dilanjutkan dengan tes terakhir, yaitu tes kualitas jalur atau biasa disebut test link. Apa saja yang diukur diantanya, jarak, dan besar redaman pada jalur baru tersebut.

Untuk pengukuran dilakukan menggunakan alat OLS dan OLP, OTDR, dan patch cord. Pertama kali pastikan jarak yang dites sudah benar jaraknya atau belum menggunakan OTDR (Gambar 17). Setelahnya kita lakukan tes redaman dengan menggunakan OLS dan OLP (Gambar 18)

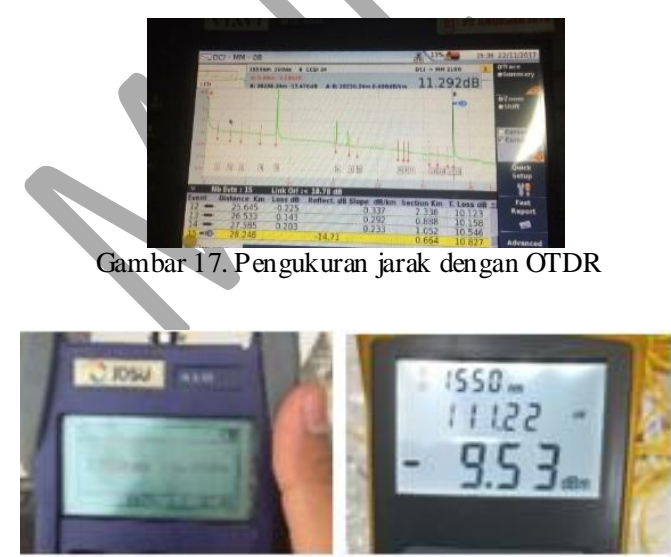

Gambar 18. Pengukuran besar redaman jalur dengan OLS (kiri) OPM (kanan)

Cara pembacaannya OLS menggunakan wavelength sebesar $1550 \mathrm{~nm}$ dan perangkat OLS memberi redaman sebesar $-3.00 \mathrm{dBm}$. Untuk OLP wavelength sebesar $1550 \mathrm{~nm}$ (harus sama dengan OLS) dan perangkat tersebut memberi tahu bahwa sepanjang jalur ini memiliki redaman jalur hingga $9.5 \mathrm{dBm}$, hasil ini bukan lah hasil sebenarnya. Hasil yang benar adalah hasil yang diterima OLP dikurangi oleh redaman perangkat OLS. Sehingga hasilnya redaman jalur tersebut :

$$
9.5-3.0=\underline{6.5 \mathrm{dBm}}
$$

Hasil sebesar $6.5 \mathrm{dBm}$ tersebut adalah bagus karena menurut International Telecomunication Union (ITU) besar toleransi redaman untuk kabel FO single-Mode dengan wavelength $1550 \mathrm{~nm}$ adalah $0.35 \mathrm{dBm} / \mathrm{Km}$.

TABEL 4 NILAI TOLERANSI REDAMANFO SINGLE MODE

\begin{tabular}{|l|l|c|c|}
\hline \multicolumn{4}{|c|}{ Cable attributes } \\
\hline \multicolumn{1}{|c|}{ Attribute } & \multicolumn{1}{|c|}{ Detail } & Value & Unit \\
\hline \multirow{2}{*}{$\begin{array}{l}\text { Attenuation coefficient } \\
\text { Note 1) }\end{array}$} & Maximum at $1310 \mathrm{~nm}$ & 0.4 & $\mathrm{~dB} / \mathrm{km}$ \\
\cline { 2 - 4 } & Maximum at $1550 \mathrm{~nm}$ & 0.35 & $\mathrm{~dB} / \mathrm{km}$ \\
\cline { 2 - 4 } & Maximum at $1625 \mathrm{~nm}$ & 0.4 & $\mathrm{~dB} / \mathrm{km}$ \\
\hline $\begin{array}{l}\text { PMD coefficient } \\
\text { (Note 2, 3) }\end{array}$ & $\mathrm{M}$ & 20 & cables \\
\cline { 2 - 4 } & $\mathrm{Q}$ & 0.01 & $\%$ \\
\cline { 2 - 4 } & Maximum PMD & 0.20 & $\mathrm{ps} / \sqrt{\mathrm{km}}$ \\
\hline
\end{tabular}

Bila semua uji coba sudah lengkap selanjutnya adalah penyatuan dokumentasi lapangan dan juga pengetesan akhir. Laporan ini selanjutnya menggantikan laporan existing sebelumnya (update). Dengan guna sebagai panduan dalam pembuatan jalur-jalur baru berikutnya atau keperluan maintenace.

\section{KESIMPULAN DAN SARAN}

1. Kesimpulan :

Berdasarkan hasil yang diperoleh, kesimpulan yang didapatkan dari Penyambungan FO Backbone pada FO Akses yaitu :

a. Rute jalur baru ini memiliki redaman jalur yang bagus sebesar $0.23 \mathrm{dBm} / \mathrm{Km}$. hasil tersebut dikatakan bagus karena memiliki redaman dibawah batas maksimal redaman yang ditetapkan oleh ITU.

b. Pada sisi ODF Mitsun dan HH, alokasi port dan core yang baru sesuai dengan konfigurasi yang dibuat sehingga proses pengerjaan tidak me mbutuhkan waktu lama.

c. Dokumentasi sangat penting untuk pembuatan jalur baru fiber optik serta pera penting dalam penetapan langkah troubleshoot, gunanya untuk mengetahui sejarah dan kondisi pada kabel yang dikerjakan.

d. Penataan kabel yang rapih membantu dalam meminimalisir redaman kabel yang berlebih. Mengingat kabel optik rentan terhadap kerusakan core akibat teku kkan. 


\section{Saran}

Dalam melakukan penyambungan FO Akses dan Backbone perlu beberapa poin yang harus diperhatikan agar kelancaran pengerjaan bisa tercapai, yaitu :

a. Pada proses pembuatan konfigurasi perlu mengumpulkan tim yang akan mengerjakan kegiatan penyambungan tersebut, baik pihak perusahaan dan vendor agar terciptanya koordinasi cepat karena sudah memiliki mengerti peran tugas masing-masing.

b. Banyak ODF yang ditemui memiliki kabel yang tidak beraturan penempatannya. Maka dari itu pengurutan kabel itu penting, selain dari sisi keindahan, kabel yang jarang tekukkannya lebih minim redaman.

\section{REFERENSI}

[1] Wahyudi, Mochmad S.Kom. 2011. Mengenal Teknologi Kabel Serat Optic. Jakarta

[2] Muchyi, Abdul. 2017. Sharing Knowledge Fiber Optic In Indosat. Jakarta

[3] Mayuda, Antaresa. Ajulian, Ajub. 2013. Fiber Optik Pada Jaringan Backbone Topologi Star Di Pt Dirgantara Indonesia Dalam Arsitektur Fttb (Fiber To The Building). Semarang 